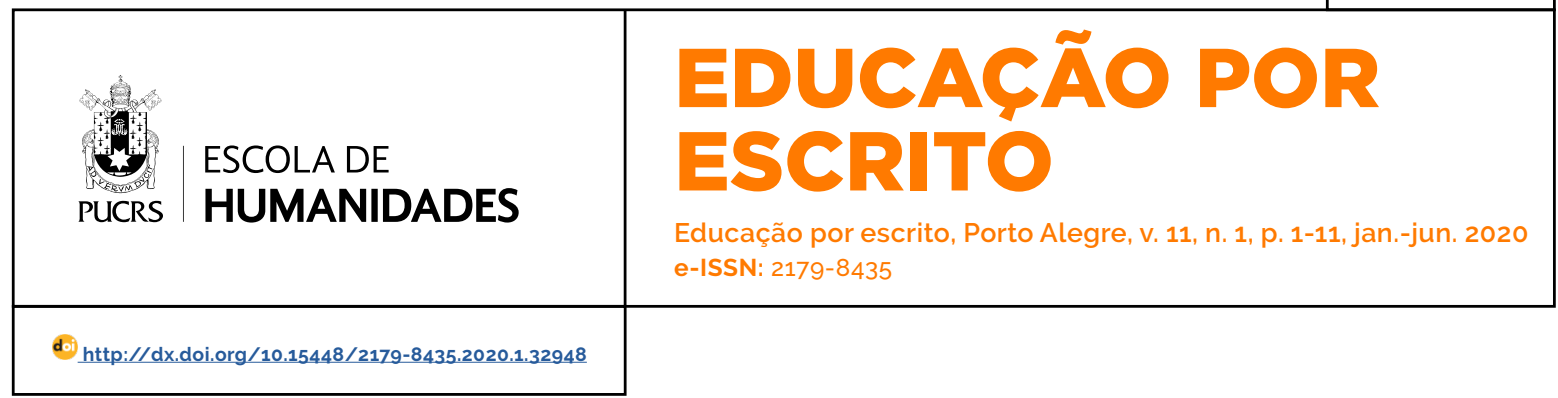

SEÇÃO ARTIGOS

\title{
A formação política do pedagogo e os níveis de consciência em Freire ${ }^{1}$
}

\author{
The political formation of the pedagogue and the levels of consciousness in Freire
}

Michele Cristina Batista

Barbado $^{1}$

orcid.org/0000-0003-2275-3786

michelebbarbado@gmail.com

\section{Renata Sieiro}

Fernandes ${ }^{1}$

orcid.org/0000-0003-2759-143X

renata.fernandes@unisal.br

Recebido em: 8 jan. 2019.

Aprovado em: 8 jan. 2020

Publicado em: 27 jul. 2020
Resumo: O objetivo deste artigo é conhecer e analisar o interesse dos/as alunos/as de um curso de Licenciatura em Pedagogia pela formação politica que impacta na visão crítica de mundo a partir dos tipos/niveis de consciência identificados por Paulo Freire. A base teórica centra-se em Freire, Gohn, Simson, Fernandes, Trilla etc. É uma pesquisa de cunho qualitativo, descritiva e analitica, do tipo participante. As técnicas envolvidas na construção de dados foram: questionário e entrevistas. A amostragem é de 40 sujeitos que cursam Pedagogia, nos períodos matutino e noturno, no ano de 2018. O lócus da pesquisa foi uma instituição de ensino superior privada no interior do Estado de São Paulo. A análise dos dados foi realizada tomando como categorias os quatro tipos de consciência apontados por Freire (1980), a saber: a consciência mágica, a ingênua, a fanatizada e a critica. Os resultados veiculados apontam para a necessária e cuidadosa formação profissional de pedagogos em tempos de crise, que sejam conscientes e críticos, participativos e ativos, que se entendam e assumam como sujeitos políticos e capazes de transformação social, pela via pessoal e dos coletivos e quando da participação na formação crítica de crianças, jovens e adultos, no campo da educação formal e não formal.

Palavras-chave: Formação política. Pedagogia. Formação de professores. Educação.

Abstract: The objective of this article is to know and analyze the degree of interest of the students of a degree in Pedagogy for the political formation that impacts on the critical world view from the types / levels of consciousness identified by Paulo Freire. The theoretical basis is centered in Freire, Gohn, Simson, Fernandes, Trilla etc. It is a qualitative, descriptive and analytical research of the participant type. The techniques involved in data construction were: questionnaire and interviews. The sample was composed of 40 subjects enrolled in Pedagogy, in the morning and night periods, in the year 2018. The locus of the research was a private higher education institution in the interior of the State of São Paulo. The analysis of the data was made taking as categories the four types of consciousness pointed out by Freire (1980), namely: the magical consciousness, the naive, the fanatized and the critical. The results conveyed point to the necessary and careful professional formation of pedagogues in times of crisis, who are conscious and critical, participative and active, who understand and assume as political subjects and capable of social transformation, through the personal and collective way and when participation in the critical training of children, youth and adults in the field of formal and non-formal education.

Keywords: Political formation. Pedagogy. Teacher training. Education.

\section{(c) (i)}

Artigo está licenciado sob forma de uma licença Creative Commons Atribuição 4.0 Internacional. 


\section{Introdução}

Este artigo, proveniente de investigação cientifica, tem como tema a formação política dos estudantes do curso de Licenciatura em Pedagogia.

A problemática enfrentada trata das práticas e processos educativos de formação política dos/as estudantes do curso de Licenciatura em Pedagogia e tem como objetivo conhecer e analisar o interesse dos/as alunos/as pela formação política que impacta na visão crítica de mundo a partir dos tipos/níveis de consciência identificados por Paulo Freire.

Desta forma, o artigo se ancora no pensamento freireano bem como em autoras da educação não formal, para sustentar a argumentação da necessidade de haver preocupação com a formação política dos futuros pedagogos que atuarão nos diversos campos da educação (dentro e fora da escola) contribuindo para formar estudantes mais criticos e humanizados que se ocupem da transformação social.

Os dados construidos permitem perceber quais são as fontes de conhecimento político de que se valem os/as alunos/as bem como sobre a presença maior ou menor de aspectos políticos na formação do pedagogo no curso de graduação em Licenciatura em Pedagogia e as implicações pessoais e sociais advindas disso.

\section{Desenvolvimento}

Para que haja a autonomia e o desenvolvimento crítico é imprescindivel que as pessoas tenham conhecimento político. Pensando que somos incompletos, essa busca pela amplitude e profundidade deve ser dar nos sujeitos politizados, Freire (2003, p. 40) "ninguém nasce feito: é experimentando-nos no mundo que nós nos fazemos" já citou isto.

Freire (1993) em seu livro Política e Educação argumenta que em uma sociedade em que o direito de ser diferente é diariamente violado, a ideia de ser uma unidade na diversidade é estilhaçada, os diferentes são frequentemente desapropriados de sua própria história.

Quando Freire trata da educação ele o faz pensando em espaços ampliados e não se restringindo a escola. Inclusive, traz o espaço do trabalho como o lugar privilegiado para a formação dos sujeitos e grupos, tanto no que toca aos conhecimentos necessários para a alfabetização quanto nos aspectos políticos e críticos. Assim, alia formação e cidadania.

Quando trata da educação, enfatiza que isso engloba tanto o papel dos professores (na escola) como de educadores (no campo da educação não formal, por exemplo) na relação com os estudantes e aprendizes.

É importante lembrar, conforme Simson, Parke Fernandes (2001), baseadas em Trilla (1996), que se tem, didaticamente, por definição a Educação Formal como sendo, basicamente a que acontece no espaço escolar, sendo normatizada pelo Ministério da Educação (MEC) tendo como principio o ensinoaprendizagem, quando existe a organização de conteúdos sob a forma de currículo e a intenção de ensinar baseada em métodos e didática.

Já a educação informal é constituída por toda a vida da pessoa em todas as situações, sem existir alguém tentando ensinar algo, com intencionalidade e método. Trata-se de todos os aprendizados adquiridos no decorrer da vida das pessoas em diferentes cenários e momentos. A maior parte do que conhecemos se dá na informalidade, na incidentalidade.

E, por fim, na Educação não formal existe uma sequência e certa organização que não é embasada no universo escolar formal, ainda que o educando, nesta prática, possa ao final de certo tempo receber o certificado daquilo que aprendeu. Essa educação não se dá em tempo e em local determinado. A aprendizagem é definida a partir do grupo e não ao contrário conforme acontece na educação formal. E não é regida e nem regulada, normatizada pelo órgão nacional que se responsabiliza pela educação formal, sendo realizada na/pela sociedade civil organizada sob a forma de movimentos sociais ou por instituições do terceiro setor.

A educação não formal lida com problemáticas que trabalham com desenvolvimento das classes sociais mais vulneráveis economicamente, porém não se restringe a elas. Frequentemente a 
educação não formal, por estar focada nos saberes e nas necessidades que os sujeitos e grupos dizem ter, se ocupa da formação social e cidadã.

Inclui, ainda, as mídias sociais, digitais impressas e sonoras. Não há como considerar que estes meios não educam. As pessoas assistem, leem, ouvem e internalizam informações e repertórios e tentam dar sentido a isso.

Segundo Fernandes (2013, p. 35), tendo Trilla como aporte,

A educação não formal é um conjunto de processos, meios e instituições especificos e diferenciados das formais, pois não visam os propósitos do sistema escolar - que tem funções definidas e socialmente aceitas. Dessa forma, a educação não formal é toda aquela que é mediada pela relação de ensino-aprendizagem, tem forma, assume e desenvolve metodologias com procedimentos e ações diferenciadas das adotadas nos sistemas formais. Nisto se incluem as midias especializadas, como as revistas, o rádio, a internet, a televisão, o cinema etc.

De forma alguma entende-se que os campos conceituais e teóricos competem entre si, mas terminam por complementarem-se.

Nos espaços educativos (o escolar e os demais espalhados pela cidade) é necessário que educadores e educadoras assumam seus postos, valorizando a diferença e a diversidade, não ignorando o conhecimento previamente adquirido e acumulado na vida de cada sujeito e dos grupos sociais. Não olhar para o educando como um simples receptáculo de conteúdo e sim como uma pessoa, um ser com conhecimentos e saberes, com percepções e entendimentos sobre coisas, pessoas, lugares.

Freire (1980) enfatiza o papel da sensibilização como mola propulsora de ações transformadoras e identifica quatro tipos de consciência:

a) a consciência mágica que se atrela ao imediato e ao premente da vida cotidiana, isenta de consciência histórica e de condições de ressignificar o passado vivido e de fazer prospecção de possibilidade de mudança. Quando o sujeito está em um círculo opressivo, acredita que vive segundo uma visão fatalista de Deus. "Deus quis assim", e segue nesse ritmo e curso sem uma perspectiva de melhora. Muitas vezes, por falta de diálogo, desconhece o passado, não tem perspectivas para o futuro. É o oprimido em seu maior grau;

b) a consciência ingênua, é considerada a fase em que o sujeito está em transição, apresenta certa capacidade de questionar o real vivido e a situação no mundo e encontra-se entre a consciência mágica e a fanatizada. É também observável como as posições políticas podem ser estruturadas e definidas a partir do momento em que o sujeito entendeu que há desigualdade social e, então, deve decidir entre não mudar nada ou tomar para si a posição de querer mudar as coisas;

c) a consciência fanatizada trata de crença e de imposição em/de opiniões próprias sem cotejamento e inclusão com a/ da diferença, o que implica acolher o dissenso e tentar impor isto a todo custo, se necessário for usando da força física. Traz em si uma ideia fechada em si mesma, não podendo haver dissenso:

d) a consciência crítica, está em um nivel diferente de conhecimento, envolve a compreensão das relações de saber e de poder que perpassam a realidade social e econômica e busca formas de mudanças das condições vigentes que mascaram e oprimem a maioria da população. A consciência crítica traz o fator responsabilidade coletiva para o sujeito, porque ele conhece, exatamente, o cenário sócio-político em que está inserido e sabe onde e o que poderia mudar para melhorar. Esse senso também o traz a consciência para que sempre se auto avalie.

Segundo Pateman (1992), para que os sujeitos possam participar ativamente na mudança de algo que não seja suficiente, inclusive ou satisfatório as necessidades básicas e de arte e cultura, é necessário que haja aprendizado disto. Faz parte de um princípio democrático e ele tem que ser vivenciado para ser aprendido. Apenas a existência e a presença de instituições nacionais representativas da população não são suficientes para garantir a democracia, porque ela tem que 
ser construida cotidianamente por todos.

A principal função da participação, segundo Pateman (1992, p. 61), "é educativa; educativa no mais amplo sentido da palavra, tanto no aspecto psicológico quanto no de aquisição de práticas de habilidades e procedimentos democráticos". Quando a pessoa participa, ela se torna corresponsável pelo que acontece porque acredita no que está fazendo, produzindo. Para que haja esta participação é necessário conhecer.

Esse exercício e vivência podem se dar em diferentes lugares e tempos, desde no trabalho, na escola, na universidade, nos grupos de sociabilidade, como em sindicatos e partidos políticos, mais especificamente.

No livro Educação não formal e cultura política, Gohn (2005), descreve um cenário de crise política e financeira brasileira, ano de 2005, em que os direitos dos trabalhadores já estavam se flexibilizando e se desregulando ${ }^{3}$.

Gohn (2014), apresenta a importância de discutir, teorizar, experimentar as novas formas de processos de aprendizagem. Para a autora, a parte do processo que consiste em aprendizagem coletiva é a que mais gera conhecimento, cooperação para com o próximo, integração e responsabilidade quando se faz necessário assumir e tomar decisões. "Em outras palavras, é participando que o indivíduo se habilita à participação, no sentido pleno da palavra, que inclui o fato de tomar parte e ter parte no contexto onde estão inseridos" (GOHN, 2014, p. 36).

Gohn (2005) acredita que para a política a melhor prática seria a democracia participativa e apenas pelo fato de que essa é o meio pelo qual os cidadãos fazem parte das decisões já seria também um grande aprendizado social. A autora volta sua defesa para a educação não formal, campo formativo onde as pessoas que estão envolvidas com esse processo conseguem aprender a autonomia, a solidariedade, relações assimétricas de poder e a possivel transformação social.
Conforme a autora (GOHN, 2010, p. 40), "na educação não-formal, essa educação volta-se para a formação de cidadãos(ãs) livres, emancipados, portadores de um leque diversificado de direitos, assim como deveres para com o(s) outro(s)". Se faz necessária a constituição de saberes político, cultural, social (GOHN, 2014).

É necessário que os sujeitos possam aprender a aprender, ou seja, desenvolver autonomia para entender, decidir, criticar, construir e se necessário for reconstruir suas ideias e aprendizado, pois só assim terão embasamento para formular seus ideais e realizar ações.

Essa situação mostra a importância de que o conhecimento político pode trazer toda a mudança para a sociedade, tanto dentro da escola como nos demais espaços educativos não formais, espalhados na cidade. Mas é necessário que os sujeitos tenham conhecimento crítico sobre as políticas aplicadas em sua sociedade para que saibam contestar frente o que lhe é apresentado ou imposto bem como reivindicar o que é necessário e desejável.

Segundo Fernandes (2013, p. 45),

A cidade é, de fato, o lócus de todo esse aprendizado, e, ao mesmo tempo em que educa, educa-se. Portanto, é muito importante pensar naquilo que podemos fazer de forma democrática e socializada, gratuitamente, de preferência, que nos chega pelos sentidos e pela experiência direta ou mediada.

Em todos os lugares e a todo momento acontece a educação, já que tudo colabora para a formação, socialização, humanização e subjetivação dos sujeitos.

É através da educação e formação que a cidadania é construida. Se a educação é a ferramenta mais importante para sensibilizar os sujeitos aprendizes, torna-se palpável e necessário que na formação do pedagogo esteja incluida a perspectiva política e crítica.

Em Freire (1993, p. 37) "a melhora da qualidade da educação implica a formação permanente dos

\footnotetext{
3 Atualmente, a crise política e financeira no Brasil tomou proporções gritantes e o cenário de direitos do trabalhador está sendo colocado à prova. Percebe-se isto, entre outros motivos, quando da configuração e realização do impeachment da presidenta Dilma Rousseff sem haver provas indicativas de fraude política e econômica, o golpe midiático, as políticas impostas pelo governo substitutivo em termos trabalhistas e previdenciários a favor da elite empresarial e contra os trabalhadores, algumas manifestações populares nas ruas contra essas ações impopulares
} 
educadores". É possivel notar como estes assumem o papel de mediadores no processo educativo. Portanto, pensar a formação tanto de professores quanto de educadores é importante e relevante. É assumir a responsabilidade pelas pessoas e pelo mundo, fazendo-se "educadores orgânicos".

\section{Metodologia}

Os resultados contemplados neste artigo provêm de uma pesquisa de abordagem qualitativa, sendo descritiva e analítica quanto aos seus objetivos, do tipo participante.

As técnicas envolvidas na construção de dados são: a) questionário no Google Docs; e b) entrevistas individuais com roteiro semiestruturado.

Para a elaboração do questionário foram observados os seguintes aspectos: a) importância (ou não) atribuida à formação política; b) o entendimento do que é formação política; c) relevância e necessidade desta estar contemplada no currículo ou extra currículo da formação universitária em Pedagogia; d) locais, tempos e pessoas ou grupos, mídias pelas quais se (in)forma; e, e) tipo/nivel de consciência que assume ter

Para as entrevistas pessoais, o roteiro semiestruturado tratou de contemplar os seguintes tópicos: a) importância (ou não) atribuida ao conhecimento dos candidatos a cargos politicos eletivos; b) conhecimento os planos de governo em campanha; c) fontes de busca das informações sobre seus candidatos; e, d) capacidade de engajamento político.

A amostragem dos sujeitos pesquisados foi construida a partir do interesse de participação dos estudantes das turmas de $1 .^{\circ}, 3 .^{\circ}$ e $5 .^{\circ}$ semestres dos períodos matutino e noturno, no de 2018, do curso de graduação em Licenciatura em Pedagogia, constituindo 40 alunos, de um total de 171 alunos.

O lócus da pesquisa foi uma instituição de ensino superior privada, de grande porte, com campus espalhados pelo Brasil, localizada no interior da capital de São Paulo, mantido por entidade religiosa.

O objetivo do curso de Pedagogia nesta instituição investigada é, de acordo com o site institucional, de modo resumido, formar profissionais com o compromisso social de lutar pela cidadania e educação de qualidade, atendendo exigências educacionais de forma democrática e participativa. Isto denota princípios humanistas de base, que coadunam tanto com o pensamento de Paulo Freire e da escola democrática como com os princípios estruturantes da educação não formal, ambos campos de atuação do egresso da Pedagogia, tanto na área da docência/educativa, quanto na da gestão.

As categorias de análise de ambas as etapas contaram com algumas categorias sociológicas como: gênero, idade, etnia, religião, participação em grupos extra universidade, semestre cursado etc. Para o questionário online serviram de categorias analíticas os quatro tipos/niveis de consciência apontados por Freire (1980), a saber: a consciência mágica, a ingênua, a fanatizada e a crítica.

O ano vigente de realização da pesquisa é marcado por uma singularidade mais que importante e relevante ao tema de investigação: o ano eleitoral. A eleição do país foi realizada para indicação de presidente e vice-presidente da República ainda foram eleitos governador e seu vice de estado e do Distrito Federal, senador, deputado federal, estadual e distrital. A escolha da população foi realizada no dia 7 de outubro de 2018 e com votações de decisão de segundo turno foram realizadas em 28 de outubro.

\section{Análise dos dados}

De modo geral, do total da amostragem, 26 estudantes do curso de Graduação em Licenciatura em Pedagogia do campus e curso escolhidos que responderam ao formulário, contam com idades que variam entre 17 a 56 anos.

A religião predominante dos pesquisados é a católica seguida da de evangélicos; a frequência é baixa a religião espírita e não há menção a religiões de matriz de terreiro. Há os que não se definem.

Em sua grande maioria se definem como brancos, sendo apenas que uma pessoa respondeu como sendo amarelo e uma pessoa respondeu como 'todas' as cores de pele.

No tratamento das análises, os quesitos idade, 
religião, etnia e gênero não foram significativos. As análises significativas se encontram por meio de comparação dos semestres.

Quando o assunto é formação política, os futuros pedagogos acreditam ser um tópico indispensável, porém, quando se trata de buscar esse tipo de conhecimento e se inteirar do que está acontecendo no cenário brasileiro ou mundial afirmam que raramente buscam esse tipo de informação.

Sobre quais disciplinas oferecidas pela matriz curricular do curso tratam da formação política, apenas um sujeito diz não saber, dois citam Filosofia, e os demais citam: Perspectiva da Profissão Docente, Educação Infantil, Educação e Meio Ambiente, Antropologia, Sociologia, Educação Étnico-Raciais e Pedagogia Salesiana.

Quando a pergunta é se os professores das disciplinas citadas anteriormente promovem debates sobre o tema, um sujeito não respondeu, um responde afirmativamente (citando que o lugar é a sala de aula) e um responde negativamente, justificando acreditar que deva ser por causa da quantidade de conteúdo a ser ministrado (entendendo, desta forma, que a formação política é algo a parte e não parte fundante do tratamento dos conteúdos).

Sobre os professores promoverem esses espaços a maioria dos sujeitos é enfática ao dizer que quando o assunto surge o/a professor/a permite que se continue e incentivam o debate. Seguem citando palestras, cine-debates (que são atividades fora do currículo do curso, mas que visam trazer temas atuais e emergentes para conhecimento e discussão, incluindo palestrantes e debatedores profissionais convidados), rodas de conversa e a própria sala de aula como espaços para estes assuntos, categóricos e unânimes em citar que não é o suficiente para formar uma opinião própria. Dois sujeitos afirmam que não há espaço.

Dessa forma é possivel pensar que alguns professores especificos incluem informações e debates politicos em suas disciplinas, por entenderem que faz parte de uma formação transversal ou de base para os conteúdos que ministram e que fazem parte das ementas daquelas, mas que não é algo que caracteriza a formação do pedagogo neste curso de graduação em Licenciatura especifico, focado neste estudo.

Um ponto importante a se observar são as disciplinas citadas pelos sujeitos como abordando a temática de formação politica. Foram as mais citadas: Filosofia, Sociologia, Antropologia (incluindo a Antropologia Cultural e Teológica), seguidas de História da Educação, Didática, Gestão Escolar e Políticas Públicas. As que foram menos citadas Perspectivas da Profissão Docente, Pedagogia Salesiana, Relações Étnico Raciais, Geografia, Educação Infantil I, Educação e Meio Ambiente.

As disciplinas citadas são as que os sujeitos afirmam abrir um pequeno espaço, mas frisam que não é suficiente para que se forme uma opinião final sobre o assunto, pois, a aula precisa respeitar a estrutura e atender o conteúdo da disciplina. Claramente que as disciplinas citadas são poucas perto da matriz curricular presente no curso.

Atualmente, a matriz curricular do curso de Licenciatura em Pedagogia investigado é composta por 69 disciplinas, distribuidas em três núcleos propostos pelas Diretrizes Curriculares Nacionais (DCN): núcleo de estudos básicos; núcleo de estudos diversificados; núcleo de estudos integradores e se subdividem nas seguintes áreas: Fundamentos da Educação; Gestão Educacional; Gestão Pedagógica; Gestão das Práticas de Ensino e Gestão do Desenvolvimento Pessoal. Sendo 66 disciplinas presenciais e apenas três disciplinas no modo Ensino a Distância (EaD), distribuídas ao longo de oito semestres ou quatro anos, totalizando 3760 horas.

Outro ponto importante a citar é que os sujeitos que referiram Sociologia são, em sua maioria, do 5 . $^{\circ}$ semestre e cursaram a disciplina em modo presencial, sendo que esta disciplina para o curso do $1 .{ }^{\circ}$ e $3 .^{\circ}$ semestre é, atualmente, oferecida em modo de EaD, e é notável que não foi citada.

É possivel perceber, que mais da metade dos sujeitos afirma ser indispensável a formação política do pedagogo, mas assume não buscar informações sobre o tema ou não consegue opinar qual disciplina poderia ter para auxiliar essa formação e, mais ainda, alguns não conseguem 
opinar ou enxergar onde está presente o tópico da política na formação atual.

Desta forma, aponta-se para a necessidade de cursarem disciplinas que contenham em sua base apoios teóricos para se conhecer e interpretar a realidade, já que o papel do pedagogo não é apenas conhecer a Didática para dar aulas, mas auxiliar na formação de sujeitos atuantes na vida em sociedade. Poderia se pensar se tais disciplinas se adequam ao modelo EaD, ou se não por necessitarem da presença e encontro para debates e discussões, mas como não foi incluida esta pergunta no questionário, não é possivel especular sobre as respostas.

Uma resposta extraída do questionário anônimo ajuda a perceber que é necessário conhecer melhor para entender o papel da universidade da formação acadêmica:

\begin{abstract}
[...] apesar de ser uma instituição religiosa, ela não é uma instituição fechada e nem faz proselitismo isso é importante porém acho que é pouco, pouco, e é claro que também poucos alunos aproveitam isso, então talvez, não sei, se tivesse outras maneiras de conseguir inserir a política não de forma, de forma conscientizada por que assim as pessoas não leem os planos de governo dos candidatos delas pra começo de conversa então a gente tá numa sala de pedagogia e tem pessoas defendem um determinado candidato que assim o plano de educação é medonho pra alguém que estuda pedagogia entende? Então são essas coisas que eu acho que talvez um curso politizado poderia resolver. ${ }^{4}$
\end{abstract}

Esse depoimento reflete a importância da qualidade da formação do pedagogo e aponta para o compromisso e a responsabilidade que o curso de Licenciatura em Pedagogia tem nisso.

Quando a pergunta é se o tempo fornecido, atualmente, para conversas e debates com essa temática são suficientes para que o/a aluno/a consiga formar seus próprios conceitos sobre o tema, a resposta "não" é frequente, justificando que o tema é complexo e amplo demais. Isso ajuda a mostrar que o conhecimento e o debate político não devem se restringir a disciplinas especificas ou ficarem a cargo de professores pontuais, mas ser uma marca da formação do futuro pedagogo. Isso vem a reforçar a necessidade dessa abordagem no currículo do curso tanto quanto nas atividades extra.

Para os sujeitos os locais de busca de informações de política são: televisão, internet e a própria universidade, ou seja, respectivamente, fontes dispostas no campo da educação não formal (as midias) e fontes dispostas no campo da educação formal, mostrando como ambos os campos teórico-conceituais se complementam e apontando a necessidade de haver essa conexão de informação e debate para aprimorar o discurso e entendimento político, preocupando-se com o pedagogo que pode ser um militante da área ou um engajado/ativista.

Para a pergunta embasada no conceito de consciência de Freire (1980), e pelas respostas dos sujeitos é possivel perceber que o/a aluno/a, no percurso formativo, desde o ingressante até o em fase de egresso, apresenta deslocamento de pensamento indicando mudança, embora haja persistência, para alguns (uma minoria) nos modos iniciais de pensamento. Isto indica que os/as alunos/as ingressantes se alocam mais no nivel de consciência definido por Freire (1980) como consciência mágica e do meio do curso para o final, oscilam entre o nível da consciência ingênua e o da consciência crítica.

Observando as respostas no aspecto longitudinal, ou seja, ao longo do percurso do curso de graduação em Licenciatura, percebe-se que os/ as alunos/as têm uma mudança nítida sob a forma crítica desde quando entram no curso até quando já estão prestes a se formar, mesmo que pequena é uma parcela de deslocamento significativa.

Isto é um ponto muito positivo, pois demostra que realmente o/a aluno/a está no caminho de refletir sobre o tema, sua realidade e a capacidade de criticar o que, onde e como vive, tornandose um cidadão com ação e participação e não apenas espectador da realidade e repetidor do convencionado, buscando mudança e a não manutenção ou conservação do status quo. E isto se mostra extremamente importante na figura do futuro pedagogo, professor ou gestor da

4 Arquivo da pesquisadora (2019). 
Educação, área que necessita de militantes ou engajados/ativistas para trazer contribuições efetivas em termos de políticas públicas e de formação no cotidiano, para qualquer público e em qualquer lugar.

Isto ajuda a mostrar que o curso universitário e, especialmente, o curso de Pedagogia estudado, podem contribuir significativa e qualitativamente para a reflexão, complementando e enriquecendo ou tencionando o que trazem como discursos e informações das fontes do campo da educação não formal e, inclusive, ampliando as possibilidades de indicação de fontes alternativas às grandes mídias que detêm o poder de veiculação de dados e interpretação de fatos.

Na sequência do percurso metodológico foram realizadas as entrevistas individuais com parte da amostragem, sendo 15 estudantes que participaram por livre e espontânea vontade.

As entrevistas trouxeram valiosas percepções e dados para a pesquisa, e também sensibilizou alguns dos/as entrevistados/as, que a menos de uma semana das eleições, ao pararem para responder, perceberam o quanto a política é importante e o quanto o conhecimento sobre o assunto em questão era restrito e limitado ou amplo e variado.

No encontro com os entrevistados e ao conhecer suas posições era possivel observar um receio de serem julgados por não terem uma opinião definida ou um candidato preferido. Logo, este receio era seguido da frase mais ouvida durante a pesquisa, "é que eu não gosto de falar sobre política", seguida pela justificativa "eu não entendo muito bem do assunto" e "mas acho muito importante". No decorrer da entrevista as mesmas pessoas que disseram antes não gostar se mostraram muito mais confiantes em expor suas opiniões.

As duas primeiras perguntas eram para entender se o entrevistado já havia escolhido seus candidatos a presidente, senado e câmara, e entender o que conheciam de seus planos de governo. Para presidente e vice, apenas dois entrevistados conheciam e apenas o plano de governo de seu candidato. Nesse ano eleitoral, de 2018, houve 13 candidatos à presidência, dos quais apenas 4 tiveram grande visibilidade na mídia aberta. Pensar que o sujeito conheça apenas $1 / 13$ dos candidatos e suas propostas pode levar a algumas considerações como ter uma preferência por determinado candidato, pelo partido em que este está inserido, ou considerar apenas os que estão em evidência na mídia.

Para a imensa maioria dos entrevistados, os candidatos à Câmara e ao Senado eram totalmente desconhecidos. Os entrevistados reconheceram a importância dos cargos, mas também reconheceram com certa resistência que não conheciam os candidatos.

A pergunta seguinte era para entender se o entrevistado conhecia e identificava qual era a melhor proposta para as áreas da educação e social. Grande parcela, perto da maioria, respondeu não conhecer e uma porcentagem baixa (13\%) respondeu conhecer de um dos candidatos, os seus eleitos, mas em seguida disseram que não iriam votar no candidato em questão porque acreditavam que seu candidato não tinha força/ vantagem política suficiente em termos de votos para ganhar e que votariam em candidatos de frentes semelhantes, porém que estavam em mais evidência, sendo tanto de orientação progressista, comumentemente denominada "à esquerda" como de orientação conservadora, comumentemente denominada "à direita".

Pelos dados a maior parte dos entrevistados respondeu não conhecer as propostas dos candidatos na integra, mas demonstra que alguma coisa eles ouviram e conheceram de alguns candidatos.

Outras perguntas foram feitas com o intuito de saber as fontes de busca de informação. Esse ano eleitoral, de 2018, contou com 7 debates de presidenciáveis e a quase totalidade dos entrevistados assistiu entre 1 a 3 deles. As fontes midiáticas mais citadas para isso foram, igualmente, internet (acessando parcelas dos debates) e televisão (assistindo a totalidade), sendo que, neste caso, a emissora mais citada foi a TV Record.

Após entender se conheciam os candidatos, as melhores propostas e onde buscavam informações, a próxima pergunta era para entender se já haviam definido seu candidato 
$53 \%$ afirmaram objetivamente que sim e $47 \%$ ainda em dúvida.

Quando questionados se já havia candidatos definidos para Senado e Câmara apenas um participante respondeu que tinha o candidato definido e mesmo este entrevistado é o que respondeu que segue o partido político, logo, ele estaria apenas seguindo seu partido político.

Outra pergunta visava saber se os entrevistados haviam mudado de escolha de candidatos em algum momento durante a campanha. A quase totalidade deles afirma que mudou, o que mostra que, mesmo afirmando que não gostam do assunto estão buscando e acessando informações de modo a embasar a escolha política pela via democrática.

Procurando saber se são afiliados ou simpatizam com algum partido político, a imensa maioria respondeu que não. Este também é um dado muito importante uma vez que entender como as cadeiras políticas são ocupadas é influência direta no que será decidido nos três poderes (legislativo, executivo e judiciário). 0 baixo interesse mostra que, na atualidade, essa instituição representativa não tem sido valorizada ou tem tido baixa credibilidade, especialmente, pelos jovens. Segundo dados sobre juventude nos partidos políticos houve diminuição em 44\% em 8 anos e duas das justificativas dadas se refere a estrutura burocrática e a hierarquização, que implica em rigidez (O ESTADO DE S. PAULO, 2018).

A pergunta que visava saber se os entrevistados partilhavam as suas opiniões com outras pessoas e por quais meios, menos da metade respondeu que sim, e a forma privilegiada é a oral e não as redes sociais.

Por fim, é perceptivel pelas falas que os sujeitos desejam um país melhor e, para tanto, é preciso conhecimento e posicionamento políticocrítico, dessa forma, os/as alunos/as passam a entender a importância da formação política acadêmica, buscando contextualizar as situações, entrelaçando realidade e teoria, entendendo que toda postura e pensamento são políticos, que não há neutralidade e que toda a omissão é manutenção do status quo.
Ora, se tanto pelas relações pessoais diretas quanto pelos meios/midias audiovisuais as pessoas aprendem e se educam, nos campos teóricoconceituais denominados de educação informal, não formal e formal, cabe à formação universitária, especialmente às que formam os futuros pedagogos, abordar efetivamente os temas, conteúdos, argumentos nas disciplinas da matriz curricular, tanto sob a forma transversal como disciplinar.

Também vale dizer que outras instituições também são lócus de formação e que os estudantes poderiam procurar aprender nesses espaços espalhados pela cidade. A participação em outros grupos e coletivos permite a ampliação do repertório de conhecimento e põe em xeque opiniões de senso comum ou os niveis iniciais de consciência definidos por Freire (1980) e apontados anteriormente.

A busca por fontes extraoficiais ou alternativas, bem como a habilidade de entender pelas entrelinhas fazem parte da constituição do sujeito político, que duvida, que critica, que questiona e isso é aprendido.

Pelas narrativas dos sujeitos, faz-se necessário conhecimento e discussão sobre o papel e funcionamento do Estado e do governo, bem como sobre a participação cidadã e o exercício democrático.

Muitos falaram que não gostam de discutir política, subentendendo que não apreciam o embate, as discussões e os desentendimentos e brigas, mas demostraram também que a recusa se dá pela falta de conhecimento ou domínio seguro sobre o assunto bem e o que muitos expressaram por diversas vezes foi a importância do respeito mútuo ao se falar sobre política partidária.

\section{Considerações finais}

O objetivo do artigo foi apresentar dados que permitissem conhecer e analisar o interesse pela formação política dos/as alunos/as do curso de Licenciatura em Pedagogia de uma instituição privada de ensino superior do interior do estado de São Paulo.

A isso buscou-se atrelar os impactos na visão crítica de mundo a partir dos tipos/niveis de consciência identificados por Paulo Freire, 
mostrando que em longo prazo os/as alunos/as apresentam deslocamentos cognitivos e críticos após o contato com conteúdos, discussões que permeiam as disciplinas, mas especialmente, pela mediação de determinados/as professores/as que se colocam como provocadores de senso crítico.

Para além de se centrar nas posturas de determinados/as professores/as que fazem de seu exercício docente também um lugar de engajamento no campo educacional, é preciso que os cursos de Licenciatura em Pedagogia, assumam e incorporem em sua matriz curricular disciplinas especificas bem como debates transversais que promovam o conhecimento da realidade nacional e internacional em termos geopoliticos, e o papel do Estado, do governo e da sociedade civil na transformação do mundo. No caso específico de um curso universitário privado, tão importante quanto se repensar as metodologias de ensino é assumir o compromisso ético e a responsabilidade social com mudança social, especialmente para minimizar desigualdades advindas do capitalismo e do modelo neoliberal imposto e assumido no Brasil desde os anos 1980 a partir de referenciais norte-americanos, da Escola de Chicago.

Entendendo que a educação acontece em todos os espaços e tempos, dentro e fora das instituições, especialmente pela via das mídias, é importante criar condições de os/as estudantes/as saberem buscar fontes alternativas de informação, para além das dominantes, hegemônicas, como modo de contrapor argumentos e informações e construir espírito crítico.

Também é importante, assumir e vivenciar outros espaços e locais extra acadêmicos, em baixa, atualmente, para os jovens, como os sindicatos e partidos políticos, como possibilidades formativas, bem como os coletivos da sociedade civil (de classe, de gênero, étnicoracial etc.) e espaços de representatividade, como Centros Acadêmicos.

Outros dois aspectos merecem ser considerados, sendo o primeiro: a ênfase dada, na atualidade, ao EaD, a tecnologia tem facilitado o acesso a regiões e localidades remotas, bem como tem permitido as informações chegarem nas casas das pessoas em seus tempos de não trabalho, entretanto, nos casos em que a presença é possivel, ela é detentora e promotora de afetos e sensações, elementos constitutivos da subjetividade e é pelo contato com a alteridade, com o diferente, que o conhecimento se torna diverso e múltiplo, assim como é a reunião de pessoas que favorece tomada de iniciativas e mudanças, ou seja, de reflexão e ação, fatores necessários a uma postura critica e engajada socialmente.

O segundo aspecto diz respeito à limitação da formação dos pedagogos tomando como base as habilidades listadas na Base Nacional Comum Curricular (BNCC), que na reestruturação para a confecção do documento suprimiu uma formação ampliada e humanista em prol de uma formação técnica e aplicada, fazendo do pedagogo um amortecedor das tensões e heterônomo, atendendo aos interesses mercadológicos privatistas, como vem apontando Freitas em seu blog.

Os resultados veiculados apontam para a necessária e cuidadosa formação profissional de pedagogos em tempos de crise, que sejam conscientes e críticos, participativos e ativos, que se entendam e assumam como sujeitos politicose capazes de transformação social, pela via pessoal e dos coletivos e quando da participação na formação crítica de crianças, jovens e adultos, no campo da educação formal e não formal.

Os resultados também podem contribuir para se repensar o currículo do curso de graduação em Licenciatura em Pedagogia, reconhecendo a importância da formação crítica e politica de pedagogos, e as implicações advindas de outra vertente formativa assumida subentendida como manutenção do status quo e reafirmação do capitalismo e do neoliberalismo como política de exclusão, de violência e de morte, no dizer de Achille Mbembe (2018).

\section{Referências}

CORREIA, Wilson; BONFIM, Cláudia. Práxis pedagógica na filosofia de Paulo freire: um estudo dos estádios da consciência. Trilhas Filosóficas: Revista Acadêmica de Filosofia, Caicó-RN, v. 1, n. 1, p. 55-56, jan./jun. 2008. 
FERNANDES, Renata Sieiro. A música acontecendo pela educação informal e não formal: como se vai aprendendo a escuta da música e a fazer música. In: SOUZA, Eduardo Conegundes de. (org.). De experiências e aprendizagens: educação não formal, música e cultura popular. São Carlos: EdUFSCar, 2013. p 29-50. https://doi.org/10.22533/at.ed.8491912071.

FREIRE, Paulo. Política e Educação. São Paulo: Cortez Editora, 2003.

FREIRE, Paulo. Conscientização: teoria e prática da libertação: uma introdução ao pensamento de Paulo Freire. São Paulo: Cortez \& Moraes, 1980. https://doi. org/10.18616/ce.v7i2.3742.

FREITAS, Luiz C. de. BNCC: uma base para o gerencialismo-populista. 2017. Disponivel em: https:// avaliacaoeducacional.com/2017/04/07/bncc-uma-base-para-o-gerencialismo-populista/. Acesso em 7 jan. 2020. https://doi.org/10.26512/2015.11.t.19319.

GOHN, Maria da Gloria. Educação não formal e cultura política. 3. ed. São Paulo: Cortez. 2005. 101 p.

GOHN, Maria da Gloria. Educação não formal, aprendizagens e saberes em processos participativos e cultura política. Investigar em Educação - II a Série, Porto, n. 1, 2014

LÜDKE, Menga; ANDRÉ, Marli. Pesquisa em educação: abordagens qualitativas. São Paulo: EPU, 1986.

MBEMBE, Achille. Necropolítica. São Paulo: n-1 edições, 2018.

O ESTADO DE S. PAULO. Número de jovens filiados a partidos políticos cai $44 \%$ em 8 anos. Disponivel em: http://infograficos.estadao.com.br/focas/por-minha-conta/materia/numero-jovens-filiados-partidos-politicos-cai-anos. Acesso em: 7 jan. 2020. https://doi. org/10.11606/t.48.2011.tde-10082011-144625.

PATEMAN, Carole. Participação e teoria democrática. Rio de Janeiro: Paz e Terra, 1992.

SIMSON, Olga R.; de M. von; PARK, Margareth B; FERNANDES, Renata S. (org.). Introdução. Educação não formal: cenários da criação. Campinas: Ed UNICAMP, 2001

TRILLA BERNET, Jaume. A educación non formal e a cidade educadora. Dúas perspectivas (unha analitica e outra globalizadora) do universo da educación.

Revista Galega do Ensino, Especial: A educación no século XX, [S. L.], n. 24, p. 199-221, set. 1999.

TRILLA BERNET, Jaume. Introducions. In: ZAINK, Maria Amélia Sabbag (org.).; SCHAWARTZ, Avi et al. Cidades Educadoras. Curitiba: Ed UFPR. 1997. p. 13-34.

\section{Michele Cristina Batista Barbado}

Graduada em Comunicação Social pela Faculdade de Americana (FAM, Americana, SP, Brasil), licencianda em Pedagogia pelo Centro Universitário Salesiano de São Paulo (UNISAL, Americana, SP, campus Maria Auxiliadora, Brasil).

\section{Renato Sieiro Fernandes}

Pedagoga, mestre, doutora e pós-doutora em Educação pela Universidade Estadual de Campinas (UNICAMP, Campinas, SP, Brasil), docente no programa de Mestrado em Educação e na Graduação em Pedagogia do Centro Universitário Salesiano de São Paulo (UNISAL, Americana, SP, campus Maria Auxiliadora).

\section{Endereço para correspondência}

Michele Cristina Batista Barbado

Rua Goiânia, 1769

Planalto do Sol,13454-335

Santa Barbara D'Oeste, SP, Brasil

Renata Sieiro Fernandes

Rua Osvaldo Guilherme, 138, lote 6

Village Campinas, 13085-728

Campinas, SP, Brasil 